\title{
Corrigendum: Something about the V Engines Design
}

\author{
${ }^{1}$ Raffaella Aversa, ${ }^{2}$ Relly Victoria Petrescu, ${ }^{1}$ Antonio Apicella, ${ }^{2}$ Florian Ion Tiberiu Petrescu, ${ }^{3}$ John Kaiser \\ Calautit, ${ }^{4}$ Ronald B. Bucinell and ${ }^{5}$ Bilal Akash
}

\author{
${ }^{1}$ Advanced Materials Lab, Second University of Naples, Naples, Italy \\ ${ }^{2}$ IFToMM, ARoTMM, Bucharest Polytechnic University, Bucharest, Romania \\ ${ }^{3}$ Department of Mechanical Engineering, University of Sheffield, Sheffield, United Kingdom \\ ${ }^{4}$ Union College, United States \\ ${ }^{5}$ Dean of School of Graduate Studies and Research, American University of Ras Al Khaimah, United Arab Emirates
}

Correction to: American Journal of Applied Sciences

http://doi.org/10.3844/ajassp.2017.34.52, published online 30 December 2017;

updated 29 August 2019

The original version of this Article contained Mr. MirMilad Mirsayar as a Co-

Author. Mr. Mirsayar has not contributed to the preparation and publication of this

manuscript.

These errors have now been corrected in the HTML and PDF versions of the Article. http://doi.org/10.3844/ajassp.2017.34.52. 